\title{
O SMARTPHONE E O IDOSO CONECTADO: RELAÇÕES ENTRE HEURÍSTICAS DE USABILIDADE E RECOMENDAÇÕES DE DESIGN DA INFORMAÇÃO
}

\author{
SMARTPHONES AND CONNECTED OLDER PEOPLE: THE \\ RELATIONSHIPS BETWEEN USABILITY HEURISTICS AND \\ INFORMATION DESIGN RECOMMENDATIONS
}

\author{
Marcos Souza Filho', Mestrando \\ Solange Coutinho' ${ }^{2}$ PhD \\ Fábio Campos ${ }^{3}$, PhD
}

(1)Universidade Federal de Pernambuco

e-mail: contato@marcostenorio.com

(2) Universidade Federal de Pernambuco

e-mail: sol2015ufpe@ gmail.com

(3) Universidade Federal de Pernambuco

e-mail: fc2005@gmail.com

\begin{abstract}
Design da informação, usabilidade, idosos, smartphones.
O propósito desse artigo é estabelecer relações entre o design da informação e a usabilidade de smartphones para usuários idosos. A partir da pesquisa bibliográfica, foram coletadas diversas publicações para identificar um fio condutor do pensamento que converge para a proposição de melhorias nas interfaces dos sistemas móveis.
\end{abstract}

Information design, usability, elder people,smartphones.

The aim of this paper is to establish relationships between information design and the usability of smartphones for elder users. From a review of the literature, several publications were collected in order to seek a thread that converges with the aim of improving the interfaces of the mobile systems.

\section{Introdução}

Pouco se fala no Brasil sobre questões de usabilidade em smartphones com foco no usuário idoso, mas é importante lembrar que esse público está em crescimento atualmente, em uma pesquisa da ONUBR (2017), estima-se que a população com idade acima de 60 anos mais que duplicará até 2050. Ainda assim, empresas de vários segmentos parecem ignorar as necessidades específicas dessa parcela da população.

Com relação à tecnologia, público idoso possui peculiaridades que não são atendidas pelas configurações dos dispositivos existentes no mercado mundial. No Brasil essa situação é ainda mais grave, pois não existem pacotes de acessibilidade e usabilidade nos smartphones produzidos nacionalmente, o que pode gerar exclusão social dos idosos (ROCHA \& PADOVANI, 2016). Imaginamos que os desenvolvedores possuem pouco conhecimento e compreensão sobre como criar interfaces de toque adequadas para idosos, eles se limitam às ações básicas dos smartphones sensíveis ao toque como tocar, arrastar movimento de pinça, que foram adotados mais recentemente. Assim, percebe-se que são necessários novos guias de desenvolvimento apoiados por pesquisa empírica para ajudar a desenvolver interfaces amigáveis para idosos (KOBAIASHI et al. 2011). Seguindo esse pensamento, Cybis et al. (2015) atentam para a necessidade de modificar elementos da interface para adequá-las ao público que enfrenta problemas relacionados à visão, audição e limitação de movimentos.

Independente da idade, absorvemos informação 


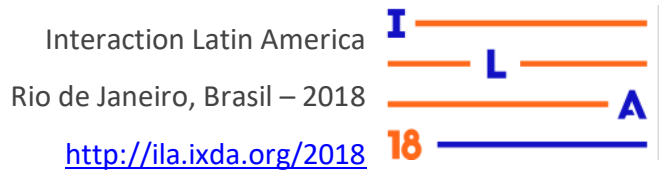

visual de diversas formas e os processos psicológicos e cognitivos envolvidos nessa ação são de extrema importância para a compreensão efetiva da informação. Dondis (2007) desenvolve uma abordagem acerca do processo de percepção e, aquilo que ela denomina de alfabetismo visual, em seu livro, Sintaxe da Linguagem Visual, com uma preocupação central acerca da comunicação visual, seja pelas imagens e/ou formas, ou dessa informação como conteúdo. Gomes Filho (2004) ainda disserta sobre a necessidade de estudar o processo de desenvolvimento do artefato informacional e chama à responsabilidade do designer para assegurar a boa composição e distribuição de elementos informacionais em padrões organizacionais compatíveis com a estrutura cerebral.

Com a popularização da informática, os computadores deixaram de ser utilizados apenas por cientistas e programadores e começaram a ser utilizados por profissionais de outras áreas e usuários domésticos, de forma sucinta podemos dizer que surge nesse momento a necessidade de preocupar-se com a forma como os artefatos digitais deveriam ser projetados. Na década de 1990, pesquisadores como Jakob Nielsen e Rolf Molich desenvolveram uma lista de dez recomendações que poderiam ser utilizadas por desenvolvedores e designers para averiguar o nível de usabilidade dos sistemas computacionais que eram desenvolvidos.

Questões como a usabilidade e a legibilidade de um sistema digital são influenciadas diretamente por elementos informacionais existentes nos projetos e, tanto quanto o funcionamento do sistema. O cuidado com o design da informação em um artefato digital deve ser meticulosamente pensado para garantir o uso adequado por uma gama maior de usuários, independente da faixa-etária. Ainda que sendo autores relacionados principalmente a usabilidade, as questões acima expostas discorrem sobre elementos informacionais, desde textos, ícones, formas, cores, até movimentos e sons, isso tudo é informação e não deve ser negligenciada para nenhum público.

Até então, não se percebe uma justificativa plausível para excluir o público idoso desse tipo de avaliação. Do ponto de vista da economia os dados corroboram com a necessidade e até a viabilidade de propostas de melhorias da interface de smartphones para idosos, visto que no Brasil, de acordo com dados do censo 2010 do IBGE (2011), já identificava que o público idoso possuía quase $20 \%$ do poder de compra do Brasil e a tendência era crescer. Durante a pesquisa, havia 24,85 milhões de pessoas com mais de 60 anos, o que correspondia a 12,6\% da população. Estima-se que até 2030, o grupo com idosos será maior do que o de crianças até 14 anos no Brasil. Com base nesses elementos, é possível observar que, seja por poder aquisitivo ou por inclusão dos artefatos digitais no cotidiano desse público, é importante assegurar que ao projetar um smartphone, as questões relativas a esse público sejam requisitos obrigatórios para os desenvolvedores e designers.

O fato de otimizar as informações em telas, já evidenciam a importância do design da informação em artefatos digitais. Esta informação, quando tratada de forma adequada, pode influenciar diretamente no poder de decisão do usuário, assim como pode afastá-lo do aplicativo ou website, ocasionando no insucesso e inviabilidade do mesmo.

A partir da problemática apontada anteriormente e de forma a cercar o problema central de pesquisa empreendemos um levantamento teórico, que encontra-se descrito a seguir.

\subsection{Percurso da pesquisa bibliográfica}

Foi desenvolvida uma revisão da literatura a fim de identificar o estado da arte do design da informação relacionando as recomendações encontradas às questões de usabilidade em interfaces digitais. Com base no proposto por Lakatos \& Marconi (2003), inicialmente foram escolhidos os temas da pesquisa a partir de palavras-chave e também pela busca em referências bibliográficas das publicações identificadas. A busca iniciou-se pela base de dados da Revista Infodesign, repositórios institucionais de universidades e nos anais de congressos da área. Ao identificar a necessidade de buscar mais refinada, o escopo da pesquisa foi ampliado e novas bases de dados foram incorporadas, a saber: Elsevier, Scopus e Google Acadêmico. Para garantir a atualidade das publicações, foi definido que o período para a busca concentra-se-ia de 2013 a 2017, englobando os últimos cinco anos.

Utilizamos as seguintes palavras-chave para as buscas: Usabilidade, Heurísticas, Design da Informação, Idosos, Smartphones nos repositórios nacionais e Usability, Smartphone, Elderly, Heuristics, Information Design nos sites 
internacionais. A partir da identificação das publicações mais atuais em diversos repositórios de teses e dissertações, periódicos e anais de congressos científicos foi possível identificar o atual andamento das pesquisas no campo da usabilidade em interfaces digitais e em design da informação. Com o levantamento em mãos, fomos em busca de teorias do design da informação que se preocupam com a compreensão e percepção dos artefatos informacionais. Para isso, identificamos os principais autores e teóricos das duas áreas e ampliando o escopo para uma busca mais refinada em livros e periódicos acima de cinco anos de publicação. Em posse dessas publicações, foi possível elencar as principais teorias e recomendações de estudos que servirão de base para responder aos objetivos desta pesquisa.

Este artigo encontra-se organizado em cinco partes, sendo a primeira relativa a problemática do envelhecimento e a sua relação com as tecnologias, de forma concisa; a segunda referente aos princípios universais de visualização da informação; a terceira se refere às questões de usabilidade de sistemas digitais e recomendações para navegação digital; a quarta, trata de estabelecer as relações entre heurísticas de usabilidade e design da Informação; e por fim as considerações finais.

\section{Envelhecimento e tecnologia}

O envelhecimento causa uma série de alterações físicas e cognitivas nos humanos, que resulta na perda progressiva de algumas capacidades. As principais alterações ocorrem em três sistemas sensoriais:

Auditivo - Altera a percepção dos sons e da fala; Háptico - Diminuição da sensibilidade tátil nas mãos;

Visual - Diminuição da acuidade visual, da visão periférica, noções de profundidade, cores e capacidade de adaptação às alterações de luz.

Além dessas questões físicas, os idosos enfrentam a diminuição de aspectos relacionados à cognição que afetam diretamente a forma como eles navegam e interagem com os smartphones. De acordo com Padovani \& Moura (2008) esses processos afetam pelo menos três áreas: percepção, atenção e memória. De acordo com os autores, podemos resumir essas áreas como:

Percepção - estágio cognitivo importante para o processo de interação pois, é responsável pelo princípio da informação;

Atenção - Existem quatro tipos de atenção focada, seletiva, dividida e sustentada/contínua. Em condições normais, o usuário pode selecionar o tipo de atenção que deseja priorizar para a navegação. Memória - o processo dinâmico entre obtenção, armazenamento e consulta de informações percebidas ao longo do tempo. Pode ser de curta ou de longa duração. Durante o processo de navegação, é utilizada a memória de longa duração para armazenar novas informações, reconhecer objetos, ambientes e tarefas.

Em sistemas hipermídia, o usuário recebe diversos estímulos visuais e auditivos, que disputam a atenção e podem dificultar a navegação do usuário. Essa diminuição das capacidades sensoriais em idosos e cognitivas altera a qualidade da navegação em sistemas digitais, deixando-os dispersos e perdidos no percurso.

\section{Princípios universais para visualização de informações}

O IIID - International Institute for Information Design é um órgão que existente desde 1986 e caracteriza o design da informação como sendo "a definição, planejamento e modelagem dos conteúdos de uma mensagem e do ambiente em que ela é apresentada, com a intenção de satisfazer às necessidades dos destinatários" (IIID, 2007). No Brasil, a Sociedade Brasileira de Design da Informação - SBDI, define Design da informação como sendo:

uma área do design gráfico que objetiva equacionar os aspectos sintáticos, semânticos e pragmáticos que envolvem os sistemas de informação através da contextualização, planejamento, produção e interface gráfica da informação junto ao seu público alvo. Seu princípio básico é o de otimizar o processo de aquisição da informação efetivado nos sistemas de comunicação analógicos e digitais. (SBDI, 2006)

Sobre o papel do designer da informação, Bonsiepe (1997) fala que ele é o responsável por organizar a informação, tornando a comunicação possível. Para fazer isso, o profissional de infodesign pode: buscar, selecionar e articular as informações; interpretar e traduzi-las para torná-las visíveis; compreender a interação entre linguagem verbal, sonora e gráfica; dominar a utilização de programas computacionais para o tratamento digital dessas informações, entre outras competências. Frascara (2004) complementa, 
adicionando o conceito de Design centrado no usuário, que parte do pressuposto de que o objetivo do artefato informacional não é a produção do artefato em si, mas a geração de reações nas pessoas, ele ainda argumenta que o designer informacional deve criar meios que possibilitem a aprendizagem, memorização, atuação, interação com objetos, outras pessoas ou informações, realizar desejos e satisfazer necessidades.

Com o advento da internet, tornou-se mais comum também falar sobre interface, conceito que surge no campo da informática como um tradutor de projetos em produtos, ele transforma sinais e códigos em informação interpretável e tem grande importância na computação gráfica, multimídia, realidade virtual e telepresença sendo, assim, um dos principais artefatos produzido pelo designer neste meio. Nesse caso, segundo Bonsiepe:

Em lugar do artefato material, coloca-se o artefato imaterial chamado informação. Um designer gráfico que projeta a diagramação de um livro não só faz, por meio do trabalho da interface, o texto visível e legível, mas também interpretável, utilizando distinções visuais: fontes, tamanhos, espaço negativo, espaço positivo, contraste, orientação, cor, articulação em unidades semânticas. (BONSIEPE, 1997, p. 145)

Ainda segundo o autor (Op.Cit.), a interface transforma a simples presença física de um objeto em disponibilidade e utilidade. Compreendendo dessa forma, Bonsiepe elaborou, à época, um diagrama que esquematiza o design como um tradutor de ações possíveis de serem executadas a partir de determinada ferramenta, compreensível pelo usuário (fig. 1):

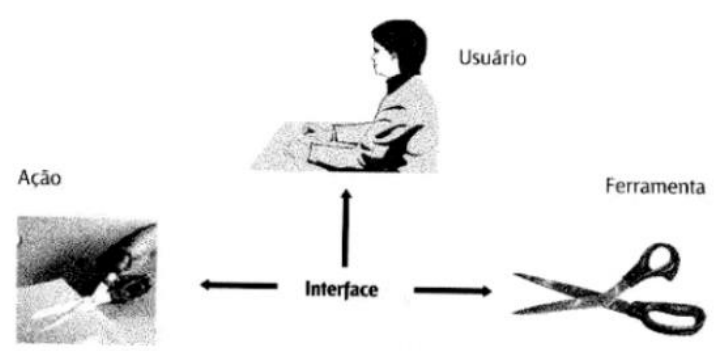

Fig. 1: Diagrama que apresenta o design como um tradutor de ações (interface). Fonte: Bonsiepe (1997, p.10).

O designer, como tradutor de códigos, sejam eles informação ou programação, deve ater-se a recomendações sobre visualização em seus projetos, esse cuidado pode assegurar a legibilidade e a usabilidade do artefato em questão. Consideraremos aqui que o designer, seja ele da informação ou digital, o responsável pela interface entre o código (mensagem) e o usuário (leitor), assim, estudaremos a seguir algumas recomendações utilizadas em projetos de design da informação e, na sequência, recomendações de usabilidade, de forma a encontrar semelhanças entre as mesmas e identificar possíveis contribuições entre as áreas.

Há algum tempo existe uma busca pela padronização da representação visual das informações. Na década de 1920, Otto Neurath (1882-1945) e sua equipe desenvolveram um sistema denominado Isotype ${ }^{1}$ que propunha a utilização de imagens simplificadas para representar informações da área social e econômica para o público geral e foi aplicado inicialmente em museus, livros, pôsteres e materiais pedagógicos implementados e testados por Marie Neurath. O propósito do Isotype era o de prover um padrão universal que pudesse ser utilizado para disseminação do conhecimento, portanto estava inerente ao sistema um processo educativo (LUPTON, 1986). Ainda segundo Lupton (1986) quando criou seu sistema de pictogramas, Neurath, imaginou que poderia substituir a interpretação de imagens pela percepção, o que poderia reduzir as distorções culturais pois, a interpretação exige o processamento mental para ser compreendida, o que pode não ser absoluto. Já a percepção faz com que a compreensão aconteça de acordo com reações condicionadas do corpo e da mente, baseadas em uma lista universal de julgamentos fundamentada nas estruturas imutáveis do cérebro e do corpo. Noutra perspectiva, todavia não conflitante, a estética da Gestalt promove um entendimento de que as formas abstratas dos elementos levam o 'leitor' à um tipo de compreensão que independe das questões culturais.

A Gestalt, conforme Gomes Filho (2004), é baseada em uma série de experimentos psicológicos e determinou algumas constantes capazes de influenciar nossa percepção e modificar o modo como enxergamos as formas, assim, as nossas forças internas prevalecem sobre as nossas forças externas e isso significa que o que percebemos nem sempre é

\footnotetext{
${ }^{1}$ O ISOTYPE - é um acrônimo para International System of Typographic Picture Education, sistema projetado por Otto e Marie Neurath e ilustrado por Gerd Arntz com o intuito de promover uma comunicação mais objetiva para o público não especialista, com ênfase na linguagem não-verbal expressa por meio de um sistema de pictogramas.
} 


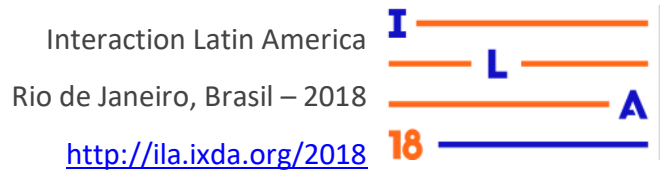

o que está impresso em nossas retinas. Segundo ele, não vemos partes isoladas, mas relações de elementos e formas, ou seja o todo. A partir dessas observações, os pesquisadores desta corrente teórica ${ }^{2}$ criaram leis, com suporte sensível e racional, para favorecer análises e interpretações da forma do objeto, que segundo eles as classificam como:

Unidade: relacionada à forma, pode ser representada em um único elemento ou em parte de um todo;

Segregação: a capacidade de reconhecer as unidades de forma separada do todo ou de partes dele;

Unificação: coesão visual entre equilíbrio, harmonia, ordenação visual e coerência da linguagem ou estilo formal das partes ou do todo; Fechamento: formação de unidades de acordo com forças de organização da forma;

Continuidade: sequência e fluidez sem quebras ou interrupções;

Proximidade: estímulos semelhantes normalmente se agrupam em unidades e constituem partes de um todo.

Semelhança: igualdade de forma e de cor cria agrupamentos de partes semelhantes;

Pregnância da forma: lei básica da percepção visual da Gestalt, trata da organização formal da imagem, equilíbrio, contraste, clareza visual.

Essas leis buscam garantir a boa percepção e leitura de formas e informações em projetos impressos e digitais (por meio da interface). O design da informação adota como base o paradigma da mediação entre o conteúdo e o usuário, criando uma espécie de interface entre ambos, mas, ainda assim existem diferenças culturais que alteram a percepção de acordo com cada público, o que dificulta a criação de princípios básicos universais do design da informação.

As leis da Gestalt têm como base a percepção da forma, que pode influenciar na compreensão da informação, mas não se atém a detalhes da sua estrutura da interface. Com isso em mente, Yuri

\footnotetext{
${ }^{2}$ A Gestalt, surge na Alemanha no início do século XX, teve como principais formuladores: Kurt Koffka (1886-1940), Wolfgang Köhler (1887-1967) e Max Werteimer (1880-1943). O termo 'gestalt', do alemão - essência ou a forma da forma completa de uma entidade, é genericamente traduzido apenas para "forma". Conhecida e aplicada no campo do design, como 'teoria da forma' ou 'teoria da boa forma', não obstante tenha surgido no campo da filosofia e se consolidado no campo da psicologia.
}

Engelhardt (2017) propõe seis ingredientes universais para a visualização de informações em representações gráficas (fig. 2), parcialmente baseados na literatura já existente sobre o assunto, são eles:

1. Qualquer representação visual de informação consiste em objetos visuais posicionados em espaços significativos;

2. Um conjunto de tipos básicos de espaços significativos pode ser identificado (Linha do tempo, Espaço do mapa, Métrica, etc) e pode ser combinados entre eles de várias formas;

3. Um conjunto de tipos básicos de objetos visuais pode ser identificado (Nó, link, rótulo, etc.) e o tipo de objeto pode ser usado para determinar como ele pode ser utilizado em relação aos espaços significativos, bem como a relação entre os próprios objetos;

4. Conjunto de tipos básicos de propriedades visuais que podem ser identificadas (tamanho, cor, forma, etc) que pode ser utilizada como codificação visual;

5. O tipo de informação a ser representada determina os tipos de espaço significativo, de objeto visual e de propriedades visuais que podem ser utilizadas para representar essa informação;

6. A combinação dessas opções citadas, de diferentes formas, produz uma grande diversidade de possibilidades de representação visual para qualquer tipo de informação.

Ingredientes universais da representação visual da informação

\begin{tabular}{|c|c|c|}
\hline $\begin{array}{l}\text { Espaços } \\
\text { Significativos } \\
\text { Espaço de Imagem } \\
\text { Espaço de Mapa } \\
\text { Linha do Tempo } \\
\text { Plano Métrico } \\
\text { Plano de ordenação } \\
\text { Plano de } \\
\text { Categorização } \\
\text { Espaço } \\
\text { proporcionalmente } \\
\text { dividido } \\
\text { Espaço do texto } \\
\text { Espaço aleatório }\end{array}$ & $\begin{array}{l}\text { Objetos Visuais } \\
\text { Nó } \\
\text { Link } \\
\text { Localizador de } \\
\text { linha } \\
\text { Localizador de } \\
\text { superfície } \\
\text { Barra } \\
\text { Container } \\
\text { Marca de Grade } \\
\text { Rótulo } \\
\text { Caractere } \\
\text { Elemento } \\
\text { pictórico }\end{array}$ & $\begin{array}{l}\text { Propriedades } \\
\text { Visuais } \\
\text { Código de tamanho } \\
\text { Código de cor } \\
\text { Código de Forma } \\
\text { Código de Brilho } \\
\text { Repetição } \\
\text { proporcional }\end{array}$ \\
\hline
\end{tabular}

Fig. 2: Ingredientes universais da representação visual proposto por Engelhardt (2017). Fonte: adaptado de Engelhardt (2017) pelos autores. 


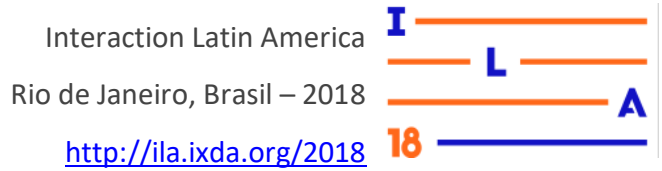

adaptado de Pettersson (2012) pelos autores.

Lipton (2007 apud DICK et al. 2017) ainda propõe oito princípios para o design da informação:

Consistência - semelhança entre elementos similares;

Proximidade - determinação correta entre os elementos no que diz respeito a relações espaciais;

Segmentação - agrupamento e separação dos elementos de acordo com seus relacionamentos; Alinhamento - disposição dos elementos;

Hierarquia - distribuição dos elementos de acordo com a importância deles;

Estrutura - relacionamento entre as partes compostas pelos elementos;

Equilíbrio e Fluxo de Leitura - direcionamento adequado do olhar do leitor;

Clareza - Redação apropriada ao público, relacionado também à legibilidade e Leitura.

Pettersson (2012), ainda apresenta diretrizes, dessa vez separadas em quatro grupos: funcionais relativos à forma de comunicar a mensagem; administrativos - relativos à administração do projeto; estéticos - relacionados com as questões estéticas; e, cognitivos - são responsáveis pela percepção, significado e compreensão da mensagem pelo indivíduo, que somam, ao todo, 16 princípios, estes apresentados na tabela seguir (fig. 3):

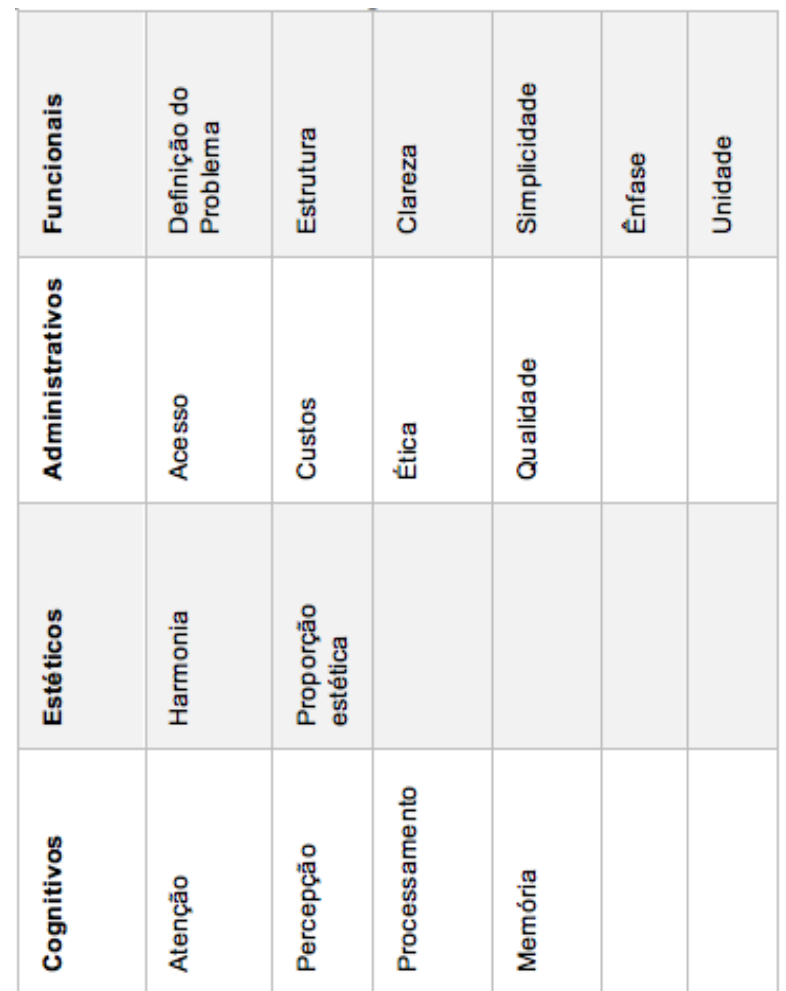

Fig. 3: Diretrizes propostas por Pettersson (2012). Fonte:
É possível perceber que a área do design da informação se preocupa com a criação de padrões e e percepção da informação em meios impressos e esses conceitos podem ser aplicados também nos meios digitais. A área da informática criou conceitos de usabilidade, ou seja, questões relativas à forma como as interfaces são utilizadas. Esses conceitos e critérios serão descritos e discutidos a seguir, no próximo tópico.

\section{A usabilidade de sistemas digitais}

Há muitas definições de usabilidade utilizadas mundialmente, a norma ISO 9241-210 (2010) define usabilidade como: o quanto um produto pode ser usado por usuários específicos, para atingir metas específicas, com eficácia, eficiência e satisfação em um contexto de uso específico. Para alcançar esses três aspectos é necessário atentar para particularidades do público-alvo do produto em questão. Além disso, é importante ressaltar a diversidade de públicos que acessam essas informações que carece de mais cuidados, não só para garantir mais acesso a dados, mas também, seguindo os preceitos do design universal - garantir que todos, incluindo pessoas com deficiência, tenham acesso aos mesmos tipos de informação que qualquer outro usuário seja no mundo físico ou virtual.

Cabe aqui definir o que se entende por artefato na área do design - como o objeto resultante do processo de configuração, sendo ele tangível ou não. Para Neves et al. (2008), o artefato digital pode ser entendido como "todo artefato material ou virtual baseado em sistemas computacionais". O artefato digital é concebido a partir de diversas partes, tangíveis e virtuais, que interagem entre elas para proporcionar ao usuário a experiência. Neves et al. (Op. Cit.) ainda complementam que o artefato digital pode ter:

pelo menos duas características importantes que os diferem de outros artefatos: as relações internas ao produto. Nos artefatos digitais estas relações mudam com a inclusão de sistemas computacionais. As relações mecânicas e eletroeletrônicas são acrescidas de relações lógicas. Regras e princípios computacionais controlam o acionamento das demais estruturas; e, no âmbito externo ao artefato, as relações também sofrem alterações significativas. Os usuários interagem não apenas com um artefato 


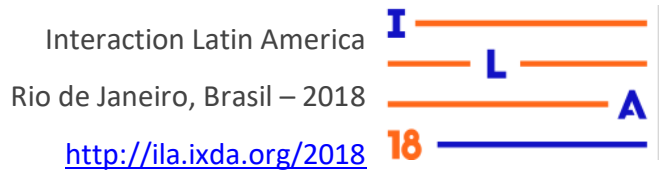

físico, mas também, e, muitas vezes, principalmente, com um artefato lógico, um sistema computacional. (NEVES et al., 2008, p. 284)

Assim, percebe-se que a utilização do artefato digital depende de, no mínimo, duas variáveis: uma física, no caso o smartphone; e a outra composta por códigos, imagens e textos, o sistema operacional instalado neste dispositivo. Diversas pesquisas estabelecem relação entre a estética das interfaces e a usabilidade percebida pelos usuários. $\mathrm{O}$ conceito de experiência de usuário surge na área de interação humano-computador a fim de proporcionar uma visão mais objetiva das relações entre os humanos e as questões estéticas, funcionais e de interação proporcionadas na utilização de sistemas interativos (CYBIS et al., 2015).

Em seus estudos sobre usabilidade em artefatos digitais, Nielsen \& Budiu (2017) perceberam que websites, não poderiam ser bem visualizados em dispositivos móveis, a partir disso, os desenvolvedores começaram a criar websites otimizados para telas móveis, com menos informações e que poderiam ser facilmente visualizados nesse tipo de dispositivo. Ainda segundo eles, com base nesses estudos e observações, iniciou-se um processo de otimizar a quantidade de informações em websites móveis de lojas virtuais, que sempre convidava a visitar sua loja física ou visitar o site completo no desktop. Essa pode ser considerada uma solução por alguns, mas, na verdade é uma forma de evitar resolver o problema em questão. Ao invés disso, o designer está abrindo mão de uma ferramenta e direcionando o usuário para outro lugar, o que pode causar problemas na compreensão ou fuga de usuários para websites melhor desenvolvidos.

É considerado um website informacional, aquele que tem por finalidade apresentar informações ou conhecimentos para o usuário, sejam eles blogs ou portais de notícias. Estes, por conter um elevado número de informações, requerem cuidados relativos a fontes, cores, ícones, cores e tratamento da informação para torná-lo mais simples e compreensível para o usuário (FERNANDES et al., 2017).

\subsection{Recomendações para navegação móvel}

Em 1993, Jakob Nielsen criou as principais heurísticas de usabilidade referenciadas até hoje por diversos teóricos, serviram de base para elaboração de outras e ainda utilizadas em algumas empresas. São recomendações que tratam de questões importantes para a usabilidade de sistemas digitais:

Visibilidade do estado do sistema - $\mathrm{O}$ sistema informa ao usuário o que está acontecendo através de feedbacks visuais ou sonoros;

Similaridade entre o sistema e o mundo real - O usuário possui repertório próprio e o sistema deve respeitar suas referências ao invés de impor novos padrões de informação como linguagem, textos, ícones e imagens;

Controle e liberdade do usuário - Permitir ao usuário controlar o sistema, ao mesmo tempo em que permite que ele desfaça alguma ação incorreta; Consistência e padrões - $\mathrm{O}$ sistema deve manter padrões em sua interface durante todo o uso independente do nível de utilização;

Prevenção de erros - Evitar erros 'importante, assim como informar como corrigi-los de forma adequada;

Reconhecer ao invés de memorizar - $\mathrm{O}$ usuário não deve ser obrigado a memorizar informações ou ações, elas estão claras na tela, assim como as instruções de como realizá-las;

Eficiência e flexibilidade de uso - A interface deve ser pensada para ser utilizada por usuários leigos e experientes com a mesma eficiência;

Estética e design minimalista - Quanto maior a quantidade de informações, maior será a sobrecarga de trabalho para o usuário, o que pode dificultar a tomada de decisões;

Ajude o usuário a reconhecer, diagnosticar e recuperar-se de erros - Oferecer ao usuário a possibilidade de desfazer ações incorretas e identificar onde errou;

Ajuda e documentação. Tornar o usuário independente de suporte, possibilitar que ele mesmo saiba executar as tarefas do sistema a partir da disponibilização de instruções que podem ser acessadas a qualquer momento.

Mesmo sendo pioneiro na criação das heurísticas, elas foram criadas pensando nas plataformas desktop, ele não as atualizou para dispositivos móveis. Em sua publicação mais recente em parceria com Budiu (NIELSEN \& BUDIU, 2017), ele apenas aplica os mesmos conceitos do desktop em smartphones e tablets, considerando elas suficientes. Ainda assim, alguns autores como Gomez et al., em 2014, as atualizaram acrescentando mais três heurísticas específicas para dispositivos móveis, são elas: 
Habilidades do usuário - O sistema adapta-se à desenvoltura do usuário mais experiente da mesma forma que se adapta ao modo de uso do novato; Interação agradável - o diálogo simples e natural, compatível com o repertório do usuário, inclui também questões de acessibilidade;

Privacidade - em uma época de tanta informação pública, é importante pensar na privacidade do usuário e segurança de seus dados.

Já Padovani \& Napo (2016) adaptam os princípios de design para ilustrar de que forma eles interferem na navegação de sistemas, o que pode ser interpretado como uma espécie de roteiro para projetos de sistemas móveis:

Atenção dividida - normalmente, quando utilizando um smartphone, o usuário não o faz como única ação, elas recomendam que as interfaces minimizem a necessidade de atenção e priorizem o reconhecimento;

Interação eye-free - eventualmente o usuário não pode olhar para a tela do smartphone quando interage, é recomendado que seja utilizado feedback tátil ou sonoro para alertar o usuário de suas ações; Interrupção - o usuário pode ser solicitado durante o uso do sistema, elas recomendam que as tarefas possam ser salvas e retomada;

Vários ambientes - o projeto deverá contemplar variação de ambientes, luz, sonoridade do espaço; Operação one-hand - possibilite ao usuário que opere o dispositivo utilizando apenas uma mão Movimentação - sempre que em movimento, o usuário não opera o dispositivo com a mesma precisão, algumas ações podem ser executadas sem controle, é recomendável que se solicite confirmação para as operações com consequências mais graves.

Entrada de dados - é mais agradável ao usuário selecionar opções ao invés de digitá-las;

Manipulação Direta - os gestos causam a sensação de controle para o usuário, sugere-se utilizá-los ao invés de comandos;

Concisão e rapidez - utilizar operações breves e objetivas;

Condução - as ações básicas devem ser auxiliadas de forma nativa, sem a necessidade de novas configurações;

Controle - oferecer ao usuário a possibilidade de voltar atrás ou cancelar ações;

Feedback - todas as ações devem oferecer respostas sobre sua execução, seja ela um sucesso ou interrompida.
Flexibilidade - pelo enorme número de usuários, o sistema deve ter opções que se adaptam aos mais diferentes perfis;

Atalhos - permitir que os usuários criem atalhos para as ações frequentes;

Estética - possibilitar alteração de aspectos estéticos do sistema pelos usuários;

Orientação - o usuário poderá optar pela orientação da tela de acordo com suas necessidades;

Lembrança - possibilidade de salvamento e recuperação de preferências do usuário;

Adaptatividade - o sistema aprende com o usuário e se adapta às suas necessidades e formas de uso; Unidade - todas as telas do sistema devem manter o padrão de elementos gráficos;

Consistência - as funções de determinados elementos devem se manter, assim como a diagramação, cores, tipografia e outros elementos informacionais;

Agradabilidade - mais que funcionar, o sistema ou aplicativo precisa agradar o usuário; Miniaturização - a interface móvel difere do desktop em diversos aspectos, isso exige a adaptação dos elementos da tela;

Metáforas - facilitam a aprendizagem de ações e ferramentas para o usuário;

Onde estou? - oferecer orientação ao usuário sobre que página ou área do sistema está sendo acessada; Gestão de erros - erros podem acontecer, mas além de serem evitados, eles precisam ter informações precisas de como proceder para corrigi-los.

\section{Estabelecendo relações entre Heurísticas de Usabilidade e Design da Informação}

Existem certas diferenças e similaridades entre os estudos em design da informação e design digital, aqui focaremos as questões relativas à Gestalt de Gomes Filho, princípios de design da informação de Lipton, diretrizes de Pettersson e à usabilidade a fim de criar uma relação entre as áreas de forma a fornecer as bases para analisar projetos com fundamentos advindos dos dois campos de conhecimento.

Como vimos ao longo do artigo, foram examinadas 33 recomendações da área do design da informação e 25 de usabilidade, com o propósito de identificar quais as similaridades que existem entre elas e quais dos pontos em que elas não convergem, com o intuito de elucidar possíveis contribuições entre ambas para o melhor desenvolvimento de sistemas pensando no usuário idoso. 


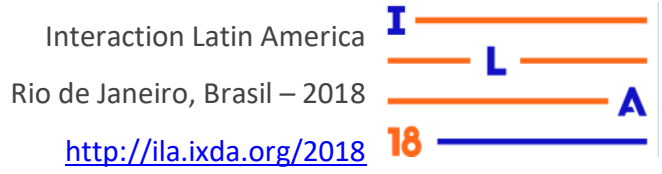

Em posse desses dados, elaboramos um gráfico com os resultados encontrados (fig. 4). Do lado esquerdo (magenta) são relacionadas as recomendações relativas ao infodesign, do lado direito (verde), as recomendações propostas por teóricos de usabilidade e design digital. As caixas de texto coloridas representam as correlações entre os dois campos, as caixas de texto com fundo branco são aquelas que não encontramos correlação entre as áreas.

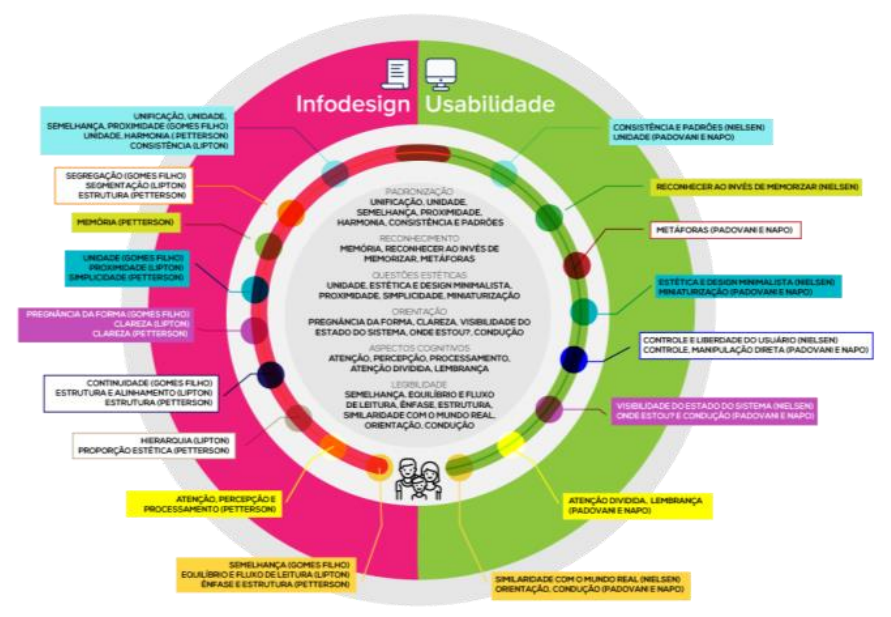

Fig. 4: Correlação por convergência ou não convergência entre as heurísticas de usabilidade e design da informação. Fonte: elaborada pelos autores.

As áreas se preocupam com a consistência e unidade das suas interfaces, além de aspectos estéticos, principalmente relacionados ao minimalismo de ícones, cores e diagramação de impressos ou websites. Um dos postulados básicos da Gestalt pregnância da forma, é relacionado de forma indireta em usabilidade quando versa sobre visibilidade dos elementos e estado do sistema, além de alusão à parte do sistema em que o usuário se encontra. Tanto um quanto o outro preocupam-se com as questões relativas à memória do leitor ou usuário, propondo recomendações para que $o$ designer se preocupe em elaborar o projeto de forma compreensível para o usuário.

É possível observar que ambas as áreas possuem recomendações semelhantes por se tratar de questões relativas à interface, entretanto fica evidente que algumas delas não são mencionadas na área de usabilidade, assim, como as observações relativas à utilização do sistema não são mencionadas em design da informação por sua não- aplicabilidade.

Algumas recomendações no campo do design da informação podem contribuir com o projeto de sistemas digitais e melhorar a experiência de usuário. Por exemplo: hierarquia, proporção estética, continuidade, estrutura e alinhamento são elencadas como recomendações importantes no design da informação e não são citadas em usabilidade. Já na área de usabilidade alguns princípios como metáforas, controle, liberdade do usuário e manipulação direta não são relacionados a nenhum dos princípios de design da informação.

A hierarquia da informação é muito importante para o infodesign mas não é considerado nas heurísticas utilizadas na área. Por mais que se trate de uma das etapas projetuais dos sistemas, é importante pensar nesse aspecto a fim de melhorar o desenvolvimento dos mesmos. Inserir recomendações sobre hierarquia da informação pode ser relevante na usabilidade dos sistemas por direcionar o olhar do usuário as informações centrais.

\subsection{Necessidades específicas do público idoso}

Os idosos têm necessidades específicas de leitura e navegação e é possível perceber que algumas delas são contempladas nas recomendações estudadas. Pregnância da forma, como preceito universal do design da informação pode ser considerada eficaz para esse público, principalmente quando se trata de alto contraste. Por conta de sua dificuldade de visão gerada pela baixa acuidade, os idosos não conseguem definir nuances de cores e as imagens com alto contraste tendem a ser mais facilmente identificáveis pelos mesmos.

As restrições de memória dos idosos podem gerar a desmotivação do uso de sistemas hipermídia, cuidar desse princípio com mais afinco pode gerar uma experiência mais agradável para eles e facilitar a utilização do sistema de forma a evitar a fuga de usuários. O idoso esquece facilmente o que estava fazendo e, tarefas difíceis de executar torna a utilização do artefato ainda mais complexo para eles.

Ambas as áreas fazem menção a aspectos da memória, a usabilidade preocupa-se mais com a questão da realização das tarefas e a necessidade de relembrar o percurso todas as vezes que o usuário necessitar; já no design da informação, apenas Pettersson preocupa-se com o aspecto cognitivo do 
usuário sobre as informações que estão sendo oferecidas. Os estudos da Gestalt preocupam-se principalmente com a percepção das informações, assim como as teorias de usabilidade, que se preocupam como o reconhecimento dos elementos da interface.

\section{Considerações Finais}

É possível observar diversas relações entre as recomendações do design da informação ao longo do tempo e as heurísticas de usabilidade e recomendações para navegação móvel. Mas é perceptível que ainda existem algumas contribuições que poderiam ser adicionadas em ambas as áreas. Diversos autores e recomendações abordam como o design da informação influencia diretamente na usabilidade de sistemas móveis, desde os específicos do design digital aos mais conhecidos da área da informação. Serão necessários outros estudos para aprofundar suas recomendações e teorias, o que extrapola o escopo deste artigo.

Não foi possível observar em nenhuma das áreas recomendações ou diretrizes para usuários e leitores idosos, o que pode ser um desdobramento dessa pesquisa em futuros estudos. Além disso recomendamos a aplicação de testes com usuários a fim de averiguar a eficácia dessas recomendações com grupos específicos de usuários e suas particularidades.

Seja por questões mercadológicas ou pela identificação do crescimento da população idosa no mundo inteiro, é necessário pensar em tecnologias que facilitem a vida do idoso. Questões como o isolamento, a depressão e a dificuldade de locomoção reforçam a necessidade de novas investigações em serviços e artefatos que possam resolver problemas que, ainda hoje, persistem com esse público. Ainda é importante salientar que, por mais imersos em tecnologia que os idosos estejam, essa geração ainda não enfrenta os problemas que as próximas gerações de idosos, nativas digitais, enfrentarão se questões como estas não foram colocadas em discussões e pesquisas futuras. Apenas trabalhar a inserção dos idosos na cultura digital não resolve todos os problemas, é necessário pensar no projeto desde o começo para que os idosos não enfrentem problemas nem fiquem sempre à margem do sistema. Muitos idosos utilizam apenas as funções mais básicas dos smartphones, muitas vezes por dificuldade em utilizar outras funções desse artefato, isso talvez ocorra, como vimos, por não haver recomendações específicas tanto nas heurísticas do campo da usabilidade quanto no campo do design da informação. Assunto a ser tratado em pesquisa futura.

\section{Referências}

BONSIEPE, G. DESIGN: do material ao digital. Trad. Cláudio Dutra. Florianópolis: FIESC/IEL, 1997.

CYBIS, W.; BETIOL, A.; FAUST. R. ERGONOMIA E USABILIDADE: Conceitos, Métodos e Aplicações. $3^{a}$ Edição. São Paulo: Novatec Editora. 2015.

DICK, M. E.; GONÇALVES, B. S.; VITORINO, E. $\mathrm{V}$.; Design da informação e competência em informação: relações possíveis. Revista Brasileira de Design da Informação / Brazilian Journal of Information Design. São Paulo | v. 17 | n. 1 [2017], p. $1-13$.

DONDIS, D. A. Sintaxe da Linguagem Visual. 3 Ed. São Paulo: Martins Fontes, 2007

ENGELHARDT, Y. Graphics with a Cause, and Universal Principles for Visualizing Information. In: ON information design [Elektronski vir] / Engelhardt ... [et al.] ; Ed. Petra Černe Oven and Cvetka Požar; Ljubljana: The Museum of Architecture and Design : Društvo Pekinpah, 2016, p. 17-34

FRASCARA, J. Communication Design: Principles, Methods, and Practice. New York: Allworth Press, 2004.

FERNANDES F. R.; BOTURA G.; PASCHORELLI L. C. Complexidade visual da interface digital e satisfação de uso: uma análise em websites de caráter informacional. Revista Brasileira de Design da Informação / Brazilian Journal of Information Design. São Paulo; v. 17; n. 1 [2017], p. $67-88$

GOMES FILHO, J. Gestalt do Objeto: Sistema de Leitura Visual da Forma. São Paulo: Editora Escrituras. $6^{\text {a }}$ ed. 2004.

GÓMEZ, R. Y.; CABALLERO D. C.; SEVILLIANO J. Heuristic Evaluation on Mobile 


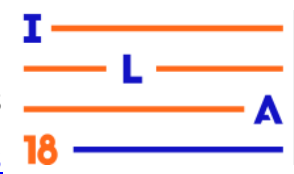

Interfaces: A New Checklist, The Scientific World Journal, Vol. 2014, ID 434326, 19 pag, 2014. doi: $10.1155 / 2014 / 434326$

IIID. International Institute of Information Design. Definitions. Disponível em https://www.iiid.net/home/definitions/ Acessado em $02 / 07 / 2018$

\section{INSTITUTO BRASILEIRO DE GEOGRAFIA E} ESTATÍSTICA - IBGE. Sinopse do Censo

Demográfico 2010. 2011. Recuperado em 28/08/2012, de http://www.ibge.gov.br/home/estatistica/populacao/ censo2010/sinopse.pdf

INTERNATIONAL STANDARD ORGANIZATION. Human-centred design for interactive systems (9241-210). Génève: ISO, 2010.

KOBAYASHI, M.; HIYAMA, A.; MIURA, T.; ASAKAWA, C.; HIROSE, M.; IFUKUBE, T. Elderly user evaluation of mobile touchscreen interactions. In: IFIP Conference on HumanComputer Interaction (p. 83-99). Springer, Berlin, Heidelberg. 2011.

LAKATOS, E. M.; MARCONI, M. Fundamentos de metodologia científica. 5. ed. São Paulo: Atlas, 2003.

LUPTON, E. Reading Isotype. In: Design Issues, Vol. 3, No. 2 (Autumn, 1986), pp. 47-58. The MIT PressStable. Disponível em:

http://www.jstor.org/stable/1511484. Acessado em: 22 de Junho de 2018.

NEVES, A. M. M.; Campos, F. F. C.; BARROS, S. G.; GALAMBA, C. Ontologia de Artefatos

Digitais para o Design. In: Anais do congresso brasileiro de pesquisa e desenvolvimento em design. São Paulo, 2008. v. 1. p. 1-1.

NIELSEN, J.; BUDIU, R. Usabilidade Móvel. 2017. São Paulo: Elsevier.

NIELSEN, J. Usabilty Engineering. Morgan Kaufmann, Inc. San Francisco, 1993.

NIELSEN, J.; MOLICH, R. Heuristic evaluation of user interfaces. Proc. ACM CHI'90 Conf., Seattle, EUA, 1-5 abril, 1990, p. 249-256.
ONUBR - Nações Unidas no Brasil. População idosa mais do que dobrará até 2050: especialista da ONU pede foco em direitos. 2016. Disponível em: https://nacoesunidas.org/populacao-idosa-maisdo-que-dobrara-ate-2050-especialista-da-onu-pedefoco-em-direitos/ - Acesso em 07/10/2017.

\section{PADOVANI, S. MOURA, D. Navegação em} hipermídia: uma abordagem centrada no usuário. Rio de Janeiro: Editora Ciência Moderna Ltda, 2008

PADOVANI, S.; NAPO, P. R. Sistemas de navegação em smartphones: um guia teóricoprático de design. Material didático instrucional de apoio à disciplina de Interação HumanoComputador. Departamento de Design, Setor de Artes, Comunicação e Design, Universidade Federal do Paraná. Curitiba, 2016.

PETTERSSON, R. It Depends: ID - Principles and guidelines. 4. ed. Tullinge, Sweden, 2012.

RIBEIRO, T. V. Estudo do equilíbrio estático e dinâmico em indivíduos idosos. Dissertação (Mestrado) - Ciência do Desporto. Área de Especialização Atividade Física para a Terceira Idade. Faculdade de Desporto. Universidade do Porto, 2009. 158 p.

ROCHA, E; PADOVANI, S. Usabilidade e Acessibilidade em Smartphones: identificação de características do envelhecimento e suas implicações para o design de interface de smartphones. Ergodesign \& HCI, v. 4, n. 4, p. 5664, 2016.

\section{SBDI - Sociedade Brasileira de Design da} Informação, 2006. Disponível em: http://www.sbdi.org.br/. 